\title{
Hitherto unreported involvement pattern of Carvajal phenotype of cardiocutaneous syndrome: evaluation on cardiac MRI
}

\author{
Arun Sharma, ${ }^{1}$ Sharmila Duraisamy, ${ }^{2}$ Niraj Nirmal Pandey, ${ }_{1}^{1}$ Sanjeev Kumar ${ }^{1}$
}

\begin{abstract}
${ }^{1}$ All India Institute of Medical Sciences, New Delhi, Delhi, India ${ }^{2}$ Cardiac Radiology, All India Institute of Medical Sciences, South Delhi, Delhi, India
\end{abstract}

\section{Correspondence to}

Dr Sanjeev Kumar,

sanjeevradio@gmail.com

Accepted 9 October 2018

\section{DESCRIPTION}

An 11-year-old boy, born out of a consanguineous marriage, was admitted with gradually progressive dyspnoea, and facial and abdominal swelling for the past 1 year. On physical examination, he had woolly hair and patchy keratosis over the palms and soles (figure 1A,B). Chest radiograph showed gross cardiomegaly (figure 1C). ECG revealed left axis deviation. Transthoracic echocardiogram demonstrated biventricular dilatation with severe left ventricular dysfunction, trabecular configuration of both ventricles along with mild tricuspid and mitral valve regurgitation. Cardiac MRI revealed biventricular dilatation with severe global hypokinesia (left ventricular ejection fraction: 10\%) and increased trabeculations in both the ventricles (figure $2 \mathrm{~A}-\mathrm{D}$ ). Late gadolinium enhanced images showed extensive transmural enhancement predominantly of septum and lateral wall of left ventricle (figure 2E-F). In addition, enhancement was also seen in the right ventricular wall as well as involving the trabeculations. No genetic study was performed in the index case. The patient was started on pharmacotherapy including beta-blockers, ACE inhibitors and diuretics. At 1-month follow-up, the patient had mild improvement of symptoms with no significant interval change in echocardiographic findings. Late gadolinium enhancement is a known risk marker for ventricular tachycardia and sudden cardiac death in adult patients. Although the same has not been well established in paediatric patients, in view of the extensive myocardial involvement putting the patient at a high risk for arrhythmias, the decision of placement of implantable cardioverter-defibrillator was taken along with continued medical management and close clinical follow-up.

Naxos disease is an autosomal recessive cardiocutaneous syndrome, initially diagnosed in families originating from the Greek island of Naxos. Characteristic triad of woolly hair, palmoplantar keratoses and arrhythmogenic right ventricular cardiomyopathy (ARVC) with classic presentation in adolescence are the hallmarks of this disease. ${ }^{1}$ Carvajal variant of Naxos disease shares these phenotypic features, however differs in presentation at a younger age with predominant left ventricular involvement (dilated cardiomyopathy) leading to early heart failure with poor prognosis. ${ }^{2}$ However, left ventricular involvement has increasingly been identified in ARVC; hence, the two entities can also be considered to be part of a spectrum of the same disease although with varying phenotypes.

Mutations in plakoglobin and desmoplakin gene have been identified as the cause of Naxos disease and Carvajal variant, respectively. Both mutations result in defects in the linking sites of the respective proteins, leading to apoptosis with progressive loss of myocardium and fibrofatty replacement. Histologically, myocardial loss with fibrofatty replacement is seen in Naxos disease while myocardial loss with fibrosis, but without the fatty component is described in the Carvajal variant. Differentiation of these phenotypically similar diseases can be performed using cardiac MRI. ${ }^{3}$ Cardiac MRI may also aid in prognostication by quantifying the degree of fibrosis which will help predict the risk of arrhythmias and sudden cardiac death.
Check for updates

\section{(C) BMJ Publishing Group} Limited 2018. No commercial re-use. See rights and permissions. Published by BMJ.

To cite: Sharma A,
Duraisamy S, Pandey NN,
et al. BMJ Case Rep
Published Online First:
[please include Day Month
Year]. doi:10.1136/bcr-2018-
227332

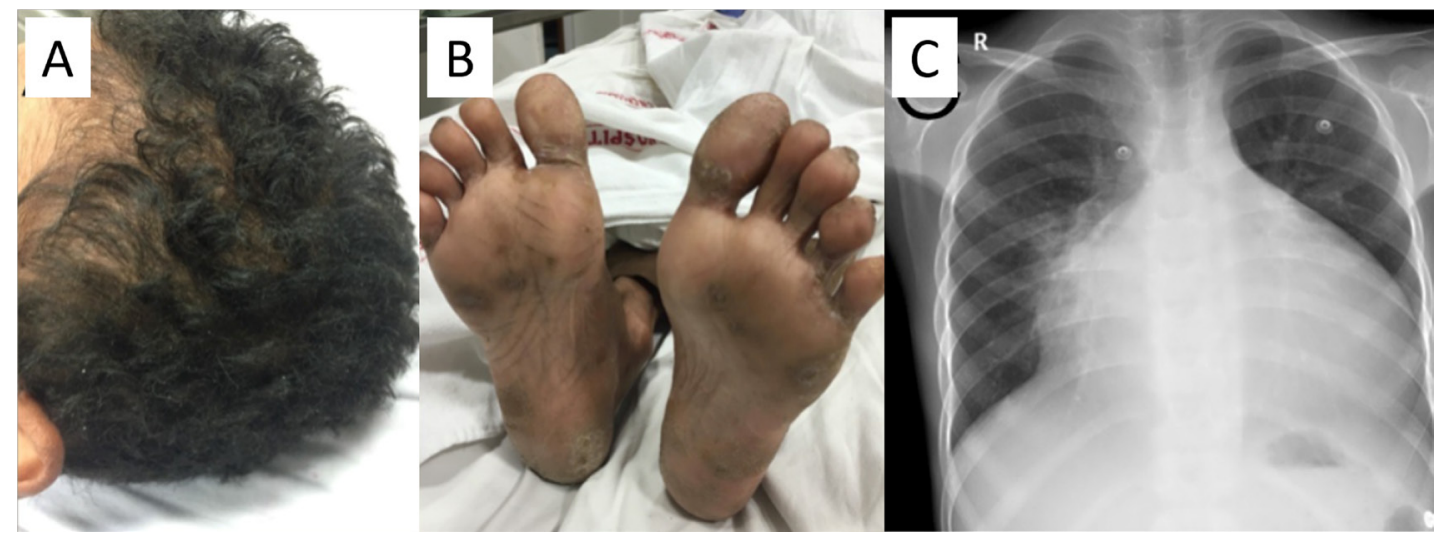

Figure 1 (A) Clinical photograph showing woolly hair and (B) plantar keratoses. (C) Chest radiograph (posteroanterior view) showing gross cardiomegaly. 


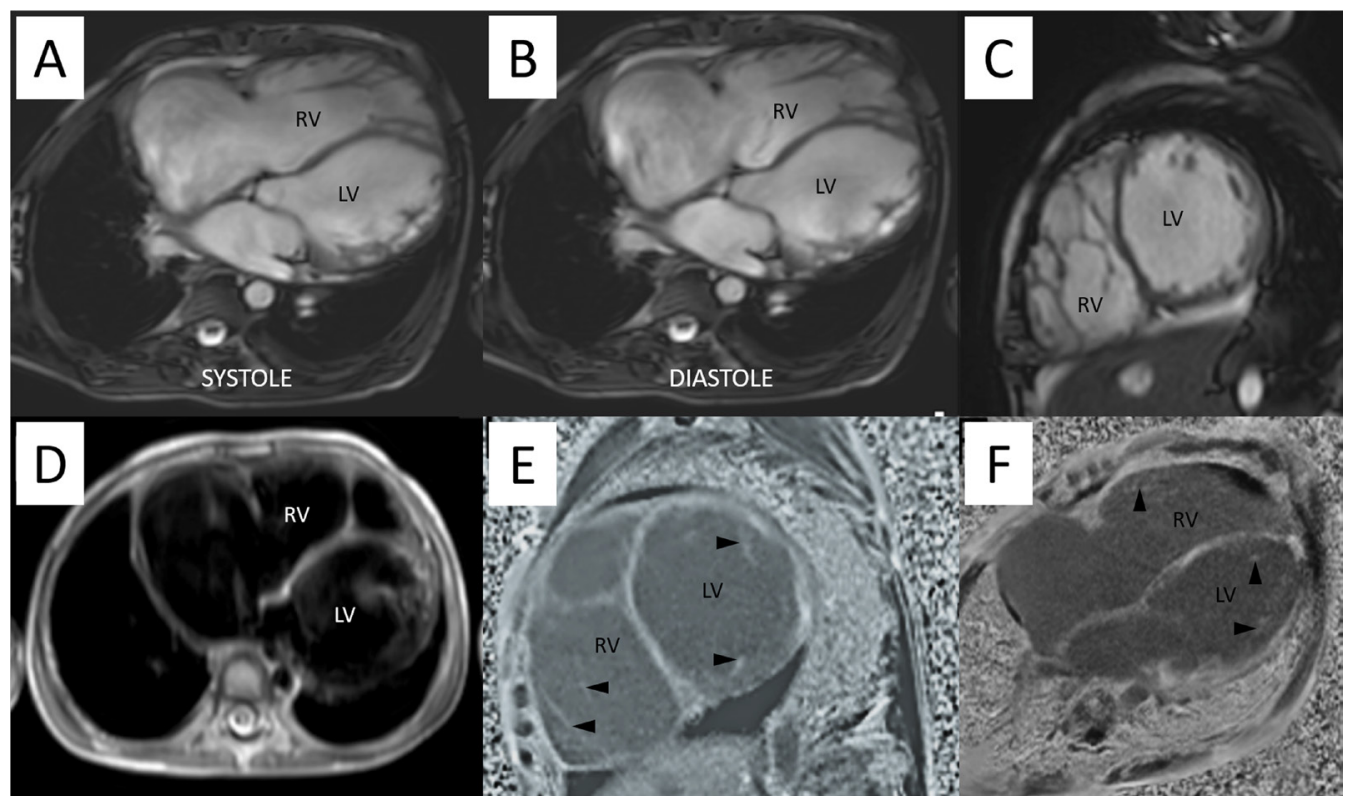

Figure 2 (A and B) Steady state free precession cine (3 Tesla), four chamber view showing dilated ventricles in systole (A) and diastole (B) with biventricular dysfunction. (C) Steady state free precession cine (3 Tesla), short axis view showing increased ventricular trabeculations. (D) Absence of myocardial oedema on T2-weighted (T2W) turbo spin echo sequence (3 Tesla). ( $E$ and F) Late gadolinium enhanced images (3 Tesla) in short axis and four chamber view showing diffuse biventricular transmural myocardial enhancement with enhancing trabeculations (indicated by arrowheads). LV, left ventricle; RV, right ventricle.

To the best of our knowledge, such extensive pattern of diffuse transmural enhancement with enhancement extending to the trabeculations as well has not been previously reported in literature.

\section{Learning points}

- Predominant left-sided dilated cardiomyopathy characterises Carvajal syndrome, compared with arrhythmogenic right ventricular cardiomyopathy in classic Naxos syndrome.

- Presentation is generally at a younger age with predominant left ventricular involvement leading to early heart failure.

- Cardiac MRI can be helpful in differentiating these phenotypically similar diseases and may predict the outcome by quantifying the degree of fibrosis.
Contributors AS, SD, NNP and SK have participated sufficiently in the conception of the idea, development of the intellectual content, design, writing and final approval of the manuscript

Funding The authors have not declared a specific grant for this research from any funding agency in the public, commercial or not-for-profit sectors.

Competing interests None declared.

Patient consent Obtained.

Provenance and peer review Not commissioned; externally peer reviewed.

\section{REFERENCES}

1 Protonotarios N, Tsatsopoulou A, Patsourakos P, et al. Cardiac abnormalities in familial palmoplantar keratosis. Br Heart J 1986;56:321-6.

2 Carvajal-Huerta L. Epidermolytic palmoplantar keratoderma with woolly hair and dilated cardiomyopathy. J Am Acad Dermatol 1998:39:418-21.

3 Prompona M, Kozlik-Feldmann R, Mueller-Hoecker J, et al. Images in cardiovascular medicine. Magnetic resonance imaging characteristics in Carvajal syndrome (variant of Naxos disease). Circulation 2007;116:e524-30.

Copyright 2018 BMJ Publishing Group. All rights reserved. For permission to reuse any of this content visit http://group.bmj.com/group/rights-licensing/permissions.

BMJ Case Report Fellows may re-use this article for personal use and teaching without any further permission.

Become a Fellow of BMJ Case Reports today and you can:

- Submit as many cases as you like

- Enjoy fast sympathetic peer review and rapid publication of accepted articles

- Access all the published articles

- Re-use any of the published material for personal use and teaching without further permission

For information on Institutional Fellowships contact consortiasales@bmjgroup.com

Visit casereports.bmj.com for more articles like this and to become a Fellow 